|| Print ISSN: 2589-7837 || Online ISSN: 2581-3935 ||

International Journal of Medical Science and Diagnosis Research (IJMSDR)

Available Online at www.ijmsdr.com

NLM (National Library of Medicine ID: 101738824)

Original Research Article

Volume 5, Issue 9; September:2021; Page No. 27-41

\title{
Investigating Maternal Mortality of the Year 2019 at Bay Regional Hospital in Baidoa, South-West State of Somalia
}

\author{
Mukhtar A. M. Yarow ${ }^{1}$, Habiba M. Mohamed ${ }^{1}$, Abdullahi M. Ahmed ${ }^{1}$, Faiza A. Ibrahim ${ }^{1}$, Hani \\ M. Hassan', Abdullahi Hassan Hussein Shegow 1, 2, 4, Adam Mohamed Nur Saman', 2, Mohamud \\ Abukar $^{1,2}$, Mohamed Aweys ${ }^{2,3}$, Adan Yare Hajir ${ }^{1,2,4}$ \\ ${ }^{1}$ Faculty of Medicine and Health Sciences, University of Southern Somalia, Baidoa, SWSS \\ ${ }^{2}$ Hakaba Institute for Research and Training, Baidoa, SWSS \\ ${ }^{3}$ Faculty of Social Sciences \& Humanities, University of Southern Somalia, Baidoa, SWSS \\ ${ }^{4}$ Bay Regional Hospital, Baidoa, SWSS
}

\section{Conflicts of Interest: Nil}

Corresponding author: Mohamud Abukar

DOI: https://doi.org/10.32553/ijmsdr.v5i9.853

\section{Abstract:}

Background: Maternal mortality (MM) has been described as a critical problem of global dimension. In 2017 alone, according to a report by the World Health Organization in collaboration with its partners (WHO et al. 2019), MM is estimated to have claimed the lives of 295,000 women worldwide. Considering this concern, the University of Southern Somalia's faculty and students from the Faculty of Medicine and Health Sciences and a faculty member from the Department of Public Administration, Faculty of Social Sciences \& Humanities of the USS, in association with Hakaba Institute for Research \& Training, Baidoa, SWSS, carried out this study to highlight the causes of MM in Baidoa City. The purpose of the study is to shed light on the extent at which cases of MM occur and the causes inherent to it by focusing on incidents at Bay Regional Hospital (BRH) in Baidoa city, SWSS, in the year 2019.

Methods: The study benefits from quantitative case study method by utilizing observation of data available in the archives of Bay Regional Hospital. Analyzing frequencies of occurrences of MM and their causes, the study uses 4 tables to demonstrate the comparisons of the incidents and causes of death from January to December 2019.

Results: A total number of 1950 pregnant women visited the hospital; 883 were consulted, treated and returned home; 1049 underwent safe delivery; while 18 women died in the process of childbirth.

Conclusion: $\mathrm{MM}$ poses a great threat to expecting mothers in Baidoa as they are exposed to the risk of dying from obstetric complications linked to numerous direct and indirect causes. Eclampsia, PPH/APH and numerous types of infections have been identified to be among the direct and indirect causes, although many of them are classified as preventable, treatable, or manageable in nature.

Keywords: Baidoa, childbirth, healthcare, maternal mortality, research, South-West State of Somalia

\section{Introduction:}

\section{Baidoa: From Harsh Life to Hope}

A glimpse at the unfavorable statistical data covering the situation of MM in sub-Saharan Africa, and particularly in Somalia, speaks also to the reality of the health situation in the South-West State of Somalia, particularly Baidoa city where Bay Regional Hospital is located. However, although from a certain point of view a sector of the society may claim that the situation in Baidoa 
is similar to what exists in other parts of the country; others with a different viewpoint would argue that it might probably be worse. For the advocates of the latter opinion, Bay has experienced, unlike other parts of the country, a situation direly complicated by the decades-old civil war and its effects, and successive periods of multiple tragedies-some manmade, others natural.

For instance, citizens of Bay Region as well as the entire Digil-Mirifle regions have experienced the darkest and deadliest period of their life during the civil war as innocent people were killed wantonly in the cross-fire of the disastrous war between armed supporters of ousted president Siad Barre's regime and armed clan militias pursuing them (Kusow 1993; Eno 2008). The number of deaths was unimaginable as urbanites were forced to flee from their dwellings. The situation was not any better in the rural area as the atrocities were extended into upcountry where villages were torched to ashes, food stored in barns and in underground bunkers were opened and looted, and foreign aid supplies were obstructed from reaching people starving in what was termed as the "City of Death" at that time.

\section{Collapse of Public Services}

Further aggravating the situation was a combination of other factors resulting from the civil war such as the collapse of the regional administrative structure, disappearance of the provision of public services, recurrent epidemics such as cholera, massive influx of internally displaced persons (IDPs), successive seasons of severe droughts and famine, devastating floods, persistent locust attacks, and a protracted situation of insecurity, to highlight just a minimum few. These multiple tragedies have taken an immeasurable toll towards the deterioration and, in some cases, the vanishing of the various infrastructures for human development such as education and health sector.

To put it in a more accurate perspective, during the civil war, Baidoa has experienced a calamitous health situation. For some time, hospitals and other health facilities were either forced out of operation or operated without drugs and medical supplies. In facilities where tiny numbers of trained health personnel were available, services were gradually but inadequately resumed. Even then, a majority of the staff continued working voluntarily without any payment for their services, until international organizations like UNICEF, Médecins Sans Frontières (MSF), SOS Children's Village (Somalia), the International Committee of the Red Cross (ICRC), and others put them in their payroll system.

In the course of time, not-for-profit local institutions like Hawl-Wadaag $\mathrm{MCH}$ facility emerged, as well as specialized child protection and welfare organizations such as Somali Children Welfare and Rights Watch (SCWRW), among others, to support the international nongovernmental organizations as effective local partners that serve the community. The picture seen here gives a reflection of how there has been very low level of healthcare services, if any, for women at childbirth during the period in discussion. Traditional birth attendants (TBAs) have, in that situation of poor maternal care, played a commendable role in assisting mothers during childbirth.

In fact, it was only after the international aid organizations arrived to the rescue of the people in this region and others in its neighborhood that some kind of hope and relief were restored. With support from foreign donors and development partners, people started to rebuild their lives by setting up administrative structures and establishing community service provision which replaced the defunct public services.

At any rate, after more than two long dragging decades, some kind of properly streamlined administrative organs were reconstituted, paving the way for the institution of the administration of the South-West State of Somalia (SWSS). The SWSS was born through an agreement that brought together the three regions of Lower Shabelle, Bay, and Bakool. Baidoa, the capital of Bay region, was chosen to be the provincial capital 
of the SWSS administration until such a time when Barawe, the official capital of the SWSS, would be able to accommodate the various organs of the administration.

\section{LITERATURE REVIEW}

\section{An Overview of Maternal Mortality}

Maternal mortality (MM) has been defined by many different scholars who mostly invoke definitions proffered by the World Health Organization. Despite that, there is no significant conflict in the meanings established except differences in style and wording. As Nigel Paneth (2012:1) explains, "Maternal mortality is defined by the World Health Organization as the death of a woman from pregnancy-related causes during pregnancy or within 42 days of pregnancy." Paneth (Ibid) adds that according to the World Health Organization (2004), maternal mortality is "expressed as a ratio to 100,000 live-births in the population being studied."

From the viewpoint of maternal mortality rate, we quote Lora Sparkman (2020, relias.com) citing WHO that: "Maternal mortality rate is the number of mothers who pass away during pregnancy or within six weeks after pregnancy is complete." Similarly citing a WHO report released in 2011, Reinke and Supriyatiningsih (2017:1) define maternal mortality as "the death of a woman during pregnancy or within 42 days after its end regardless of duration or place of the pregnancy." As Reinke and Supriyatiningsih (Ibid) further elaborate:

[Maternal mortality] is distinguished between direct and indirect cause of death. A direct death is caused by complications directly related to the pregnancy, childbirth and puerperium including interventions, omissions, insufficient treatments or their combinations. An indirect death originates from pre-existing illnesses which have worsened by physiological changes of the pregnancy.

\section{Maternal Mortality in a Global Perspective}

Maternal mortality has been identified as a major concern. In order to reduce the mortality ratio, the
World Health Organization, in collaboration with its partners, presented a "full strategy paper on ending preventable maternal mortality (EPMM)" to be included in the Sustainable Development Goals (SDGs) 2030. The document had a very ambitious goal of eradicating or at least reducing preventable mortality that would likely affect expecting mothers. As a result, the world adopted and endorsed target 3.1 of the Sustainable Development Goals 2030, with the aim of reducing maternal mortality to below 70 per 100,000 live births throughout the world (https://www.who.int/topics/sustainabledevelopment-goals/targets/en/).

In order to support the global initiative and evaluate the achievement made over the years since the adoption, the World Health Organization and its partners produced an "internationally comparable global, regional and country-level estimates and trends for maternal mortality between 2000 and 2017" (WHO et al. 2019). In a report on "global causes of maternal mortality," attributed to "a WHO systematic analysis," Say et al. (2014, e323) elaborate that within the years between 2003 and 2006, "direct obstetric causes" claimed the lives of "about 73\% (1 771000 of 2 443 000)" of women while "indirect causes accounted for $27 \cdot 5 \%(672000,95 \%$ UI $19 \cdot 7-$ 37.5) of all deaths." According to Nawal M. Nour $(2008,77)$, "Causes of maternal mortality include postpartum hemorrhage, eclampsia, obstructed labor, and sepsis."

In addition to what scholar Nour has underlined, other causes do exist that contribute to MM. Antepartum hemorrhage (APH), for instance, has been identified as another contributing factor to MM by causing the mother to bleed before birthing due to placenta previa and placenta abruption. Minna Tikkanen (2011:140) conducted remarkable research on placenta abruption by reviewing a large volume of available scholarly literature. In particular, Tikkanen analyzed "studies focusing mainly on clinical aspects of placental abruption," (Ibid,). As a result, Tikkanen writes: "Placental abruption, classically defined as a premature separation of the placenta before delivery, is one of 
the leading causes of vaginal bleeding in the second half of pregnancy," thus calling our attention to this factor as a potential cause of death (Ibid,).

Together, these factors are described to be among the most common causes of maternal mortality. However, there is need to note that sometimes death of an expecting mother may occur due to mismanagement by the medical personnel or the patients themselves, as Aden et al. (2019) found out in their study undertaken in Bosasso District in the State of Puntland, Somalia.

\section{Maternal Mortality in a Comparative Perspective}

In Somalia, maternal mortality rates are among the highest in the world. One in 12 women is likely to die during pregnancy, childbirth, or the postpartum period because of a lack of access to health services. (MSF 2019)

Researchers declare that MM does not threaten all pregnant women in the world in the same degree or at the same ratio. In the developed world, also called high-income countries, health authorities have established outstanding health policies, procedures, budgets and practices that enhance provision of healthcare. Medical and health personnel are sufficiently trained and work in hospitals and health facilities equipped with the necessary equipment and technology which allow them to provide high quality services. In particular, these countries invest considerably in research towards the improvement of maternal health and childcare. In comparison, low-income countries lack effective healthcare policies and services for their citizens such as improved maternal health services that contribute to the reduction of the occurrences of preventable, treatable, or manageable diseases that cause maternal mortality (WHO 2019; Shah 2018; Jinga et al. 2019; Nour 2008; Pheage 2017 ).

According to an examination of statistical data on maternal mortality ratio published in 2020 by Simona Varrella, Somalia is featured in the fifth place (along with Central African Republic) among African countries. The report states that about 829 Somali women die per every 100,000 live births, (Varrella, 2020). Another document, the Draft on AWD/Cholera Preparedness and Response Plan 2017-2022 by the WHO and its partners, puts Somalia's MM ratio at "732 deaths per 100,000 live births," (WHO, WASH Cluster, Health Cluster \& UNICEF, [nd] available at: https://moh.gov.so/en). Exceeded only by Southern Sudan 1,150, Chad 1,140, Sierra Leone 1,120 , and Nigeria 917, Somalia's maternal mortality ratio reveals how the situation is still very serious and much higher than many SubSaharan African countries within the low-income bracket as Somalia.

When critically analyzed, though, Somalia's situation is more serious than can be observed from a mere fifth position, given the fact that many women do not give birth in health facilities. The lack of reliable written document resulting from such births and deaths renders impossible the establishment of accurate demographic analysis and assessment of MM. In any case, the lack of data in this regard is common not only in Somalia but it also exists in many parts of the low-income nations of the world where records are either unavailable or entries are incorrectly made (Aden et al, 2018).

In general, the maternal mortality ratio (MMR) of Sub-Saharan Africa, and even of the underdeveloped or least developed countries, is much higher compared to that of the developed nations. For example, New Zealand has the lowest MM cases among the latter group by 1.7 death ratio per 100,000 childbirths, followed by Norway 1.8, Netherlands 3, Germany 3.2, Sweden 4.3, Switzerland 4.6, Australia 4.8, UK 6.5, Canada 8.6, France 8.7, and the US 17.4 (Tikkanen et al. 2020). Although this makes the USA the highest in maternal mortality among the first 10 high-income nations, it is still much better than the so-called lowincome countries. The evidence which was tracked from "reports on a wide range of health system measures across 37 high-income countries" was compiled by Roosa Tikkanen et al (2020). 
While we share a lot in common with the scholarly argument on the differences and gaps between rich and poor in healthcare systems, the reality is that women in low-income nations face more challenging living conditions and livelihood problems influenced by factors such as: poor nutrition, most of which can be related to poor income; disorderly health policy; endemic malfeasance rampantly circulating at the upper echelons of the state; and pathetic economic situation ubiquitous in every development sector in those countries (Ayittey 1998; Le Billon 2008; Addah et al. 2012; Sobrinho and Thakoor, 2019). In such a doomed situation, as Ayittey (1998) would agree, it is most unlikely to address the problems faced by pregnant mothers in the lowincome African societies as many of them cannot afford the resources to transport them to health facilities where services may be available. Articulated in another way, someone who can illafford to put on the table a single meal a day, cannot be expected to be able to pay for transportation to and from the hospital, regardless that the situation has reached the critical time of childbirth. Rationally observed, such a mother would not be expected to have spared money or saved transportation fee for the several visits required to see a doctor during perinatal period, despite that these health checkups and follow-up appointments are crucially needed.

Yet, available literature on medicine and healthcare illustrates how MM is a great tragedy in the world and in the developing countries; in particular Baidoa city, Bay Region and the SouthWest State of Somalia in general. As mentioned in a 2018 report by the World Health Organization, "The high number of maternal deaths in some areas of the world reflects inequalities in access to quality health services and highlights the gap between rich and poor," (WHO 2019; https://www.who.int/news-room/fact-

sheets/detail/maternal-mortality). Say et al. (2014:323) invoking WHO, and observing the role of policymakers and medical personnel, advise that "A key requirement for further advances in reduction of maternal deaths is to understand the causes of deaths for effective policy and health program decisions." Contextualizing its efforts toward the enhancement of maternal healthcare in Baidoa, the organization Médecins Sans Frontières (MSF) comments on the remarkable achievement realized while remaining silent on the number of mortality cases: "From May to December 2018, over 4,000 women received antenatal or postnatal consultations and over 1,500 women were admitted to the maternity ward [and that] a total of 686 babies were delivered in that eight-month period," (MSF 2019).

Maternal mortality in some of the world's poorest nations such as Somalia, and others in SubSaharan Africa as well as in a vast majority of African and Asian nations, may be a serious problem to mothers for reasons including, but not limited to: 1. Lack of or inadequacy of appropriate hospitals and well-trained medical personnel (Aden et al. 2019; CARE 2020) who can provide the health services the community so desperately requires and seeks; 2 . The fact that many, if not most, of the health facilities do not have the necessary medicines the citizens need. This reminds us why in his article in the e-Magazine Africa Renewal and entitled "Dying from Lack of Medicines," Tefo Pheage (2017:24) shares his concern by saying: "With public health facilities suffering chronic shortages of critical drugs, many patients die of easily curable diseases." Pheage's concern raises the relevance of policy considerations in health issues, not only in SubSaharan Africa, but literally in all countries where low-income people live.

\section{Policy Implications towards Maternal Mortality}

Addressing the anomalies that very often lead to maternal mortality calls for urgent attention; an attention that needs not just to be emphasized but observed and analyzed more critically from multidiagonal perspectives in finding its solution. To that effect, and prior to reflecting on other factors, Somali authorities need to (re)consider the existing health policy of the country as a whole. Specifically in the current case of SWSS, much 
attention is required to be focused on areas that cover maternal mortality or the provision of mother and child healthcare. Studying the status of the current health policies regarding maternal mortality and/or maternity care, available literature in health reports and government documents do not support the existence of credible policies thoroughly designed and effectively implemented to reduce maternal mortality to below the 70 per 100,000 live births ratio.

The reviews and analyses outlined and expressed here are not intended to deny that some policy guidelines are/may be available in one way or the other. However, the few that exist in terms of the "nation's overall development plan and policy," as highlighted elsewhere by Qayad (2007:197), have either been designed or influenced by foreign consultants under the auspices of international agencies and foreign organizations engaged in Somalia's development programs. As Qayad (Ibid,) postulates, "The nation's policies [past and present], which were [are] never based on precise facts and figures, failed to provide clear guidance to the frontline decision-makers about the overall health care mission and the driving principles of health care service delivery." Testimonials are not hard to come by as some of the references cited in this study originate from these organizations.

Evidence supporting weakness of the Federal Government of Somalia (FGS) in the various sectors under its authority needs not further emphasis. Stagnation of programs, mismanagement of communication, disorientation of implementation of existing projects, which in one way or the other affect the outcome of whatever policy or planning framed for execution, are clearly identified in reports by the Federal Government of Somalia and its development partners. Even in the case that the Ministry of Health of the FGS and its members of the Regional/State Administrations have designed attractive policies, or endorsed an imposed one by the partners, the challenges and frustrations surfacing in the implementation processes of such policies are clearly demonstrated in lamenting statements like this:
Avenues for the use of alternative technology for reporting health events in (sic) a challenge in especially lower (sic) and middle (sic) Juba since these are perceived as a security threat in most of these areas. Regional surveillance officers are deployed across the region and supported by WHO, however their incentives have not been paid for the last 6 months making it difficult for them to send data on a weekly basis. Community alerts and rumors are received from media houses. (WHO Report; accessed at: https://moh.gov.so/en/)

In another report by one of the donors and development partners, Somalia is castigated for all sorts of governance misconduct. Thus a section of an undated WHO report on the website of the Somalia NGOs Consortium reads: "Lack of accountability and transparency is among the key challenges for the health sector. Regulation of health professionals and facilities and enforcement of health regulations are almost nonexistent. Public health laws are outdated and have not been reviewed for more than 25 years." (http://somaliangoconsortium.org/)

CARE (2020, 26), one of the aid organizations operating in Somalia for so long and in many sectors, has been unequivocal on the pathetic situation of the Somali healthcare service where it found the functioning of health facilities poorly organized and much below acceptable standards. The organization highlighted how incompetent people were recruited as medical personnel and were allowed to work in healthcare facilities where drugs and other necessary medical supplies were beyond reach. These layers of multifarious inefficacies surrounding Somalia's healthcare sector, clearly expose the country's need for serious leadership that considers policy, expertise, and knowledgebase as the principle foundation for an improved healthcare system.

The above literature is testimony to the lack of capacity of the federal as well as regional governments in the different administrations. To say the least, especially from the aspects of effective management principles, designing of 
policy and mere setting of strategic plans may not sufficiently bear any fruits in the absence of trained officials with conscience and consciousness of professional ethics and the moral and material costs that come with accountability. Therefore, the deficiency of policy design, or one which is existing but dormant, only disenfranchises the overall aim of maternal health as a human right (Hunt \& Mesquita nd) and instead augments the degradation of the mortality rate of pregnant mothers.

One of the most considerable problems dominantly appearing in health service provision surrounds the untrained or inadequately trained traditional birth attends (TBAs). For instance, how effective can TBAs be in recognizing/identifying complications early enough? Secondly, can they refer a complicated obstetric case promptly to a designated hospital or health facility before its deterioration? Addressing critical issues of this nature not only require profound training, skills and expertise but equally the reaching of sound decisions to save time and life-decisions primarily dependant on effective training and acquisition of a sound knowledgebase of the profession. Accordingly, how much is the knowledgebase TBAs have on the basis of which they can make a good judgment that leads to sound decision-making toward suddenly emergent complications? Policies should be considered to remove existing barriers so as to include TBAs in the main stream of the fight against maternal mortality by training them sufficiently in order to strengthen their knowledgebase and enhance their needed skills (Miller \& Smith 2017).

The mentioning of these discrepancies is not meant to downplay in any way the role of TBAs in society, since the importance of their services has been acknowledged unequivocally, including in this study. However, although the TBAs' services may be helpful in situations of normal delivery, that alone should not drift us from the reality that they may nonetheless worsen the situation due to inadequacy of the training they undergo and therefore the poor knowledgebase that does not respond adequately and urgently during an emergency. In addition, their lack of sufficient modern skills and basic medical supplies to deal with complications that arise during childbirth (Aden et al. 2019) should be considered as a factor that poses another threat to mothers.

Observed from another viewpoint, lack of coordination and liaison with the health authorities only feeds to the TBAs' unaccountability for the quality of service they provide. Absence of constant monitoring schemes, follow-up and evaluation mechanisms, non-registration of clients as well as the uncounted numbers of casualties occurring due to their mishandling of cases-are, to name a few, among the factors that undermine the overall enhancement of maternal healthcare. In her thesis on MM in Bosaso district in Puntland, Somalia, Jamila A. Aden (2018:11) discloses the problem with lack of registry as follows:

"... a third of the maternal deaths have occurred without being registered by the service facilities and thus have been missed, as a consequence from data generated in the study one could not estimate the maternal mortality in the district

Therefore, a purposely designed policy of partnership with TBAs (Miller \& Smith 2017) outlining all relevant responsibilities and procedures profoundly explained to the stakeholding partners will contribute to curbing some of the problems undermining the provision of effective maternal healthcare services.

\section{RESEARCH METHOD}

In principle, this study follows the case study research path because it intends to investigate maternal mortality with focus on only one specific hospital, namely Bay Regional Hospital. Focusing on this targeted institution, the objective was studying and observing archival data in the hospital. More specifically, we were investigating MM among women admitted to the hospital only during the year 2019 in order "...to examine this one segment in miniature" (Liebow, 1967:16). As Neale et al. (2006:3) inform: "The case study gives the story behind the result by capturing what happened to bring it about, and can be a good 
opportunity to highlight a project's success, or bring attention to a particular challenge or difficulty in a project."

Best and Kahn (2004:193) elucidate that the case study helps "to understand [...] deeply [...] the factors that explain present status". Coming from a similar viewpoint, authors like Soy suggest that the case study is useful because it can use different methods to collect and analyze data, thereby justifying our approach for using the quantitative paradigm as one among the methods. According to Soy (1997, quoted in Eno 2012), "The case study method, with its use of multiple data collection methods and analysis techniques, provides researchers with opportunities" that can help them "strengthen the research findings and conclusions."

Bromley (1986:295) succeeds in clarifying the important fact that: "A 'case' is not only about a 'person' but also about that 'kind of person." By this statement, Bromley stresses how the case study can be employed to produce valuable and reliable data about the subject under investigation. Methodologist Kothari (2007:35) supports that the case study is best utilized to conduct a "more precise investigation..." of the subject the research is focused on. Quoting Browne (1976), Eno \& Dammak (2014:2) submit that since an investigator may conduct research without a hypothesis, the outcome of such study cannot be easily anticipated - meaning, the result cannot be predicted. Moreover, the use of the case study is common in the field of health sciences, as we enlighten in the next couple of paragraphs.

In the field of health science, "case study research has been used internationally in healthcare studies across clinical settings," (Brogan et al, 2019:446). Brogan and colleagues highlight that case study research in healthcare aims "to explore systems and processes of care delivery" (446). Moreover, Brogan and friends (Ibid.) tell us that one of the tasks of the case study approach is to provide nurse researchers with "contextualized understanding" of the matter under their observation. About a decade earlier than the work by Brogan et al.,
Anthony and Jack (2009) had underscored that the case study method has a global appeal in the field of healthcare. In the same line of thought, Payne et al. (2006) express how in the United Kingdom, it was nurse researchers who were behind the promotion of the use of the case study method in the healthcare profession.

In spite of all the above support, our preference to employ the case study method does not make us oblivious of the debate surrounding it and the scrutiny subjected to its usability. We are aware of the fact that, while it is praised by a section of scholars and users, another section has subjected it to negative criticism, according to Eno \& Dammak (2014) who reviewed a broad volume of literature on the case study debate. Among other credible works and varied views, examples of the encounters are available in Flyvbjerg $(2006,2011)$, Gomm et al., (2000), Giddens (1984) as well as in Eno and Dammak (2014).

We wrap up this section by noting that the scholarly observations reviewed in this sub-section share several things in common with the current study. One such similarity lies in the fact that when we started observing and reviewing documents in the hospital archive, we had no clue where the data would take us and what the results would be likehence supporting the above statement by Browne (1976) and Eno \& Dammak (2014). This fact can be gleaned from the observed data that we could not have had any concept of where the course of investigation would lead us to or what results the numbers and frequencies of causes of MM would produce.

\section{Data Collection}

As a matter of relevance, but also of convenience, we employed quantitative data collection and analysis techniques by way of observation of secondary data. We studied cases reported in the archival documents in the database of Bay Regional Hospital, sifting through data on MM by specifically scrutinizing occurrences and incidents in year 2019. Quantitative method gave us the opportunity to enumerate, analyze, and compare data statistically (Gibbert et al. 2008) by 
examining variances and frequencies across the months of 2019 and in terms of admissions, discharges, deliveries, deaths and causes of death. Only data related to maternal mortality were included in the methods of collection and analysis, using monthly reports of visits made by pregnant women for check up, admissions for delivery, cases of childbirth, and number of deaths recorded in the registry. Due to the targeted focus of our inquiry, excluded from the study are all data other than MM. Also not included in the data are MM incidents that occurred outside the scope of 2019.

\section{Validity and Reliability}

As we mentioned above, the case study was subjected to negative criticism. In particular, validity and reliability have been issues raised as either weak or lacking in the case study methodfactors a section of scholars claimed could undermine the very value of the method. Encountering that notion, Flyvbjerg (2006), Peattie (2001), Gillham (2000) and more recently Eno and Dammak (2014), have, among others, defended the case study regarding its validity and reliability. For instance, analyzing Flyvbjerg (2006:233), Eno and Dammak advocate: "The value of the case study will depend on the validity claims that researchers can place on their study, and the status these claims obtain in dialogue with other validityclaims in the discourse to which the study is a contribution" (Eno \& Dammak 2014:4).

In the very same article analyzing the literature on the debate over the case study, Eno and Dammak (2014:4) strongly argue that "conclusion drawing and verification" depend on how the researcher would "give meaning and interpret data." Further invoking Flyvbjerg's (2006:233) argument advocating for the validity and verifiability of the case study, Eno \& Dammak (2014:4) continue their supportive comment by saying "the benefits of the case study can be measured according to the degree at which investigators are satisfied (or dissatisfied) with the outcome of their study."

\section{ANALYSIS AND DISCUSSION}

In the next section, we present a tabulated analysis of the results in view of frequencies and percentages. The figures in the tables provide evidence that confirms the number of maternal mortality and the causes that led to the deaths as analyzed according to the monthly entries at Bay Regional Hospital in the year 2019.

Table 1: Monthly analysis of maternal mortality and its causes at BRH in 2019

\begin{tabular}{|c|c|c|c|c|c|}
\hline Month & $\begin{array}{l}\text { No. of visits by } \\
\text { pregnant women }\end{array}$ & $\begin{array}{l}\text { No. of women } \\
\text { consulted }\end{array}$ & $\begin{array}{l}\text { No. of } \\
\text { deliveries }\end{array}$ & $\begin{array}{l}\text { No. of } \\
\text { deaths }\end{array}$ & No. \& causes of death \\
\hline January & 146 & 65 & 78 & 3 & $\begin{array}{l}1 \text { Eclampsia } \\
1 \text { Hemorrhage (PPH, APH) } \\
1 \text { Obstructed Labor }\end{array}$ \\
\hline February & 134 & 51 & 82 & 1 & 1 Complicated Delivery \\
\hline March & 157 & 70 & 84 & 3 & $\begin{array}{l}1 \text { Severe Malaria with Anemia } \\
2 \text { Infection: Hemorrhage (PPH) }\end{array}$ \\
\hline April & 155 & 72 & 81 & 2 & $\begin{array}{l}1 \text { Eclampsia } \\
1 \text { Hemorrhage }\end{array}$ \\
\hline May & 218 & 96 & 118 & 4 & $\begin{array}{l}1 \text { Eclampsia } \\
2 \text { Hemorrhage } \\
1 \text { Obstructed Labor }\end{array}$ \\
\hline June & 170 & 68 & 101 & 1 & 1 Obstructed Labor \\
\hline
\end{tabular}




\begin{tabular}{|l|l|l|l|l|l|}
\hline July & 145 & 64 & 80 & 1 & 1 Severe Anemia \\
\hline August & 188 & 81 & 107 & 0 & N/A \\
\hline September & 146 & 66 & 80 & 0 & N/A \\
\hline October & 209 & 103 & 105 & 1 & 1 Eclampsia \\
\hline November & 128 & 58 & 69 & 1 & 1 Severe Anemia \\
\hline December & 154 & 89 & 64 & 1 & 1 Complicated Delivery \\
\hline TOTAL & $\mathbf{1 9 5 0}$ & $\mathbf{8 8 3}$ & $\mathbf{1 0 4 9}$ & $\mathbf{1 8}$ & $\mathbf{1 8}$ \\
\hline
\end{tabular}

With six columns and fourteen rows, Table 1 illustrates data that reveal the frequency of the occurrences in the maternity ward of Bay Regional Hospital in the year 2019. Data demonstrate that 1950 maternity-related cases were recorded in the hospital, consisting of all the women who visited the facility for maternal healthcare. Of the 1950 visitors, the hospital records reveal that 883 were consulted, treated normally and returned home, while 1049 mothers were admitted for delivery in the maternity ward. Recorded data further confirm that among the 1049 mothers registered for delivery across the 12 months of 2019,18 cases of maternal death were reported.

A month by month observation and analysis of the report compiled during 2019 elucidates that the month of May had the highest visits made - with 218 expectant mothers seeking either consultation or treatment. It has the second highest number, 96, of pregnant women returned home after either consultation or treatment. The same month of May records 118 deliveries facilitated in the hospital and stands as the month with the highest rate of delivery at BRH in 2019. Nevertheless, the report reveals 4 deaths, which makes May the month with the highest mortality cases in a single month during the year under examination.

The second month in terms of maternal visits is October which registered 209 patients. It has the highest number, 103, of mothers treated and returned home after consultation, while in terms of delivery it falls in the $3^{\text {rd }}$ place with 105 deliveries and behind August which assumed the $2^{\text {nd }}$ place after realizing 107 safe deliveries. Although October has the highest number of mothers consulted, treated and returned home, it has only a single death case which places it among February, June, July, November and December which also have a similar number of single death each in 2019. When compared against other months, April records 2 cases of death out of 155 visits expectant mothers made; 72 women were consulted, treated and returned home, while 81 women realized safe delivery without any complications during the process.

With respectively 188 and 146 prenatal visits each, August and September can be commended as the two months with zero deaths recorded in the hospital's maternal ward in the year 2019. This is a remarkable achievement because both months have respectively recorded 107 and 80 successful deliveries. Comparative to other months in the same year 2019, January and March are in the second place for maternal mortality at $\mathrm{BRH}$, with each one of them recording 3 deaths. In contrast, November has the lowest number of visits as only 128 pregnant women are registered in the records. It reported 58 prenatal checkups against 69 safe deliveries. November is positioned among the months with only a single death case and therefore better than January and March with 3 deaths each, April with 2 casualties and May with 4 . At the same time, it falls below August and September which categorically are the only two months with no reported maternal death in 2019. 
Table 2: Causes and total number of MM at BRH during 2019

\begin{tabular}{|l|l|l|}
\hline Number of deaths & Causes of death & Percentage \\
\hline 4 cases & Gestational hypertensive (pre-eclampsia and eclampsia) & $22.22 \%$ \\
\hline 4 & Hemorrhage: postpartum hemorrhage (PPH) \& antepartum hemorrhage (APH) & $22.22 \%$ \\
\hline 2 & Infections: postpartum hemorrhage (PPH) & $11.11 \%$ \\
\hline 3 & Obstructed labor & $16.66 \%$ \\
\hline Sub Total: & & $\mathbf{7 2 . 2 1 \%}$ \\
\hline 5 & Other causes/complications: & \\
\cline { 2 - 3 } & 2 cases severe anemia & $11.11 \%$ \\
\cline { 2 - 3 } & 1 case severe malaria with anemia & $5.55 \%$ \\
\cline { 2 - 3 } & 2 cases complicated delivery & $\mathbf{2 7 . 7 7 \%}$ \\
\hline Sub Total: & & $\mathbf{9 9 . 9 8 \%}$ \\
\hline Grand Total: & & \\
\hline
\end{tabular}

Table 2 illustrates the number as well as causes of MM as reported in the database at Bay Regional Hospital in 2019. It demonstrates that gestational hypertensive, (pre-eclampsia and eclampsia) and hemorrhage (PPH, APH) were reported as the highest causes of maternal death during child delivery, with each one of them claiming 4 casualties or $22.22 \%$ in the course of the year. As indicated in the results, 2 of the cases, amounting to a little over $11 \%$, were registered to have been infections related to $\mathrm{PPH}$, while 3 cases equivalent to nearly $17 \%$ were classified as obstructed labor. Data reveal that 5 cases, a little short of $28 \%$, were related to "other complications" including $11.11 \%$ severe anemia, $5.55 \%$ of the 18 mortality cases caused by severe malaria with anemia, while complicated delivery cases claimed $11.11 \%$ of the lives of mothers at childbirth. We present in Table 3 and Table 4 the direct and indirect causes of maternal mortality in accordance with the results of the statistical data distributed in Table 1 and Table 2.

Table 3: Direct causes of MM at BRH in 2019

\begin{tabular}{|l|l|l|}
\hline No. of MM deaths & \multicolumn{1}{|c|}{ Causes of death } & Percentage \\
\hline 4 & Gestational hypertensive (pre-eclampsia and eclampsia) & $22.22 \%$ \\
\hline 4 & Hemorrhage: postpartum hemorrhage (PPH); antepartum hemorrhage (APH) & $22.22 \%$ \\
\hline 3 & Obstructed labor & $16.66 \%$ \\
\hline TOTAL: & & $\mathbf{6 1 . 1 0} \%$ \\
\hline
\end{tabular}

Table 3 displays that 11 of the maternal casualties, or $61 \%$, were categorized as direct causes, mostly related to eclampsia and $\mathrm{PPH} / \mathrm{APH}$. The medical records of 2019 reveal these two are generally the main direct causes of MM in the health institution, while obstructed labor is in the second place consisting of $16.66 \%$ of the direct-causes category of maternal mortality. The results, as exposed Table 3, indicate the gravity of the situation and calls for an urgent intervention. The authorities and indeed the stakeholders engaged in the health sector statewide in SWSS should come up with an appropriate strategy that deals seriously with these causes. More importantly, addressing the direct causes of MM alone may not promise success without also giving due consideration to the effects expectant mothers suffer from as a result of the indirect causes of maternal mortality, as furnished in the next table. 
Table 4: Indirect causes of MM at BRH in 2019

\begin{tabular}{|l|l|l|}
\hline No. Of MMR deaths & \multicolumn{1}{|c|}{ Causes of death } & Percentage \\
\hline 2 & Infections of postpartum hemorrhage (PPH) & $11.11 \%$ \\
\hline \multirow{5}{*}{5} & Other causes/complications: & \\
\cline { 2 - 3 } & 2 cases severe anemia & $11.11 \%$ \\
\cline { 2 - 3 } & 1 case severe malaria with anemia & $5.55 \%$ \\
\cline { 2 - 3 } & 2 cases complicated delivery & $11.11 \%$ \\
\hline \multirow{2}{*}{ TOTAL: } & & $\mathbf{3 8 . 8 3 \%}$ \\
\hline
\end{tabular}

Categorically, Table 4 can be compared to its precedent table, Table 3 , as the opposite, considering that the current table reveals data on the indirect causes of maternal mortality. Table 4 demonstrates that out of the 7 causes reported as indirect causes of maternal death at BRH in 2019, complications arising during delivery caused 5 (27.77\%) deaths compared to infections of postpartum (PPH) with 2 cases of death. A breakdown of the causes of these 7 deaths shows that the indirect causes of maternal mortality at Bay Regional Hospital in 2019 stand as: 2 $(11.11 \%)$ cases of infections related to $\mathrm{PPH}$; $11.11 \%$ deaths from severe anemia; and that $5.55 \%$ of the pregnant mothers succumbed to death due to the compounded effects of severe malaria and anemia; while $11.11 \%$ lost their lives as a result of complications that occurred during childbirth.

A comparative analysis of the data in Table 3 and Table 4 demonstrates that there are more direct causes of MM at BRH than indirect causes - based on the established variance of 11 (Table 3) to 7 (Table 4). The respective frequencies of 11 for direct causes and 7 for indirect causes highlight not alone the disparity between the two sets of causes but even the need for a more concerted attention on how to address both. We raise this point because factors like anemia and malaria, which have higher frequency rates in the category of indirect causes, attract more attention and equal concern since these are treatable illnesses which should not cause fatalities to the extent of their current state. The findings discussed here support the literature review above that in many African countries, people become victims either of treatable diseases or due to lack of appropriate care and drugs (Pheage 2017; Aden et al. 2019). Concerning the direct causes, a timely arrival at a medical facility, enhanced obstetric as well as midwifery training for medical personnel and for traditional birth attends (TBAs) could extensively reverse the situation.

\section{Conclusion}

Maternal mortality poses a serious threat to mothers as the results of this study confirm. Out of 1049 deliveries; 18 women, equivalent to $1.7 \%$ of the 1049 mothers who delivered at Bay Regional Hospital in 2019, succumbed to death from diseases which are treatable, manageable, or preventable in nature. Viewing it from a global perspective and indeed from the perspective of the target schemed out in the Sustainable Development Goals 2030, the figure is reasonably high. The results deliver a strong message to the hospital management and the health authority of the South-West State of Somalia as well as the donor partners that support the health sector to redraw a more robust strategic plan; one with a more refined agenda that tightens the loopholes that contribute to MM, thus denying the situation to slip out of hands. Without such a strategy and a more realistic collaborative approach of all the stakeholders in the health sector, Bay Regional Hospital and the vastly expanding community of Baidoa district and its environs, the targeted mortality ratio of below 70 deaths per 100,000 childbirths by 2030 will remain far from achievable. In order to reduce MM and achieve target 3.1 of the Sustainable Development Goals 2030, health authorities and medical and health professionals need to give serious considerations to the matter in order to save more lives.

\section{Acknowledgment}

We would like to extend our gratitude to Prof. Mohamed A. Eno, and Prof Ali J. Ahmed, Prof. Abdulkadir Abu for their suggestions and support, 
and the two reviewers whose comments were useful to the study.

\section{References}

1. Addah, M.A., Chibamba, W., Jaitner, A., Koroma, E.B., Miamen, A., and Nombora, D. (2012). Poverty and Corruption in Africa: Community Voices Break the Cycle. Centre for Transparency and Accountability in Liberia, Ghana Integrity Initiative, Centro de Integridade Pública, Transparency International Sierra Leone, Transparency International Uganda, Transparency International Zambia.

2. Aden, J. A. (2018). "Maternal Mortality in Bosaso District of Somalia: Retrospective Case Study on Causes and Contributing Factors." Thesis project, Department of Medicine, Faculty of Medicines and Health Sciences, East Africa University.

3. Aden, J. A., Ahmed, H. J., and Östergren, P. (2019). "Causes and Contributing Factors of Maternal Mortality in Bosaso District of Somalia: A Retrospective Study of 30 Cases Using Verbal Autopsy Approach." Global Health Action, 12:1, 1672314, DOI:10.1080/16549716.2019.1672314. (https://doi.org/10.1080/16549716.2019.1672314) (Accessed 6 September 2020)

4. Anthony, S. and Jack, S. (2009). "Qualitative Casestudy Methodology in Nursing Research: An Integrative Review." Journal of Advanced Nursing, 65(6): 1171-1181.

5. Ayittey, G. B. N. (1998). Africa in Chaos. New York: St. Martin's Press.

6. Best, J. W. and Kahn, J. V. (2004). Research in Education ( $7^{\text {th }}$ edition). New Delhi: Prentice-Hall of India.

7. Brogan, P., Hasson, F., and McIlfatrick, S. (2019). "Lessons Learnt: Examining the Use of Case Study Methodology for Nursing Research in the Context of Palliative Care," Journal of Research in Nursing, Vol. 24(6): 446-459.

8. Bromley, D. B. (1986). The Case Study Method in Psychology and Related Disciplines. New York: John Wiley.

9. Browne, J. (1976). "Field Work for Fun and Profit." In M. P. Golden (Ed.). The Research Experience. Itasca, IL: Peacock.

10. CARE (2020) Somali Relief and Recovery Program-SRRP: Somaliland, Puntland, Galmudug and Jubbaland States of Somalia: Endline Assessment Report 2020.
11. Eno, M. A. (2008). The Bantu Jareer Somalis: Unearthing Apartheid in the Horn of Africa. London: Adonis \& Abbey Publishers.

12. Eno, M. A. and Dammak, A. (2014). "The Case Study Dilemma: Controversies and Considerations." Veritas: The Academic Journal of St Clements Education Group, 5(3): 1-8.

13. Flyvbjerg, B. (2006). "Five Misunderstandings about Case-Study Research." Qualitative Inquiry, 12(2): 219-245.

14. Gibbert, M., Ruigrok, W., and Wicki, B. (2008). "What Passes as a Rigorous Case Study?" Strategic Management Journal, 29(13): 1465-1474.

15. Giddens, A. (1984). The Constitution of Society: Outline of the Theory of Structuration. Cambridge, UK: Polity Press.

16. Gillham, B. (2000): Case Study Research Methods. London: Continuum.

17. Gomm, R., Hammersley, M. and Foster, P. (Eds.), (2000). Case Study Method: Key Issues, Key Texts. London: Sage.

18. Hunt, P. and Mesquita, J. B. de (undated). "Reducing Maternal Mortality: The Contribution of the Right to the Highest Attainable Standard of Health," University of Sussex, UK.

a. (https://www.unfpa.org/sites/default/files/pubpdf/reducing_mm.pdf) (Accessed 19 May 2021)

19. Jinga, N., Mongwenyana, C., Moolla, A., Malete, G., and Onoya, D. (2019). "Reasons for Late Presentation for Antenatal Care: Healthcare Providers' Perspective." BMC Health Services Research, 19(1016): 1-9

20. Kothari, C. R. (2004; 2007 reprint). Research Methodology: Methods and Techniques (revised $2^{\text {nd }}$ edition). New Delhi: New Age International Publishers.

21. Kusow, A. M. (1993). "Somalia's Silent Sufferers." (www.allafrica.com) at: https://allafrica.com/stories/200101080507.html (accessed 5 March 2021).

22. Le Billon, P. 2008. Corrupting peace? Peacebuilding and Post-Conflict Corruption.

23. Liebow, E. (1967). Tally's corner: A study of Negro Streetcorner Men. Boston: Little, Brown \& Co.

24. Médecins Sans Frontières (MSF) (2019). "Addressing Health Needs of Women and Children in Baidoa." https://www.msf.org/addressinghealth-needs-women-and-children-baidoa-somalia (accessed 25 March 2021) 
25. Miller, T. and Smith, H. (2017). "Establishing Partnership with Traditional Birth Attendants for Improved Maternal and Newborn Health: A Review of Factors Influencing Implementation." BMC Pregnancy and Childbirth, 17(365): 1-10.

26. Neale, P., Thapa, S., and Boyce, C. (2006). "Preparing a Case Study: A Guide for Designing and Conducting a Case Study for Evaluation Input." Pathfinder International, Tool Service Series - Monitoring and Evaluation -1.

27. Nour, N. M. (2008). "An Introduction to Maternal Mortality." Reviews in Obstetrics \& Gynecology, 1(2):77-81.

https://www.ncbi.nlm.nih.gov/pmc/articles/PMC2 505173/

28. Paneth, N. (2012). "Neonatal and Perinatal Epidemiology." In Christine A. Gleason and Sherin U. Devaskar (Eds.), Avery's Diseases of the New Born ( $9^{\text {th }}$ edition), pp. 1-9. W. B. Saunders.

29. Payne, S., Field, D., Rolls L, Hawker, S. and Kerr, C. (2007). "Case-study Research Methods in End-of-Life Care: Reflections on Three Studies." Journal of Advanced Nursing, 58(3): 236-245.

30. Peattie, L. (2001): "Theorizing Planning: Some Comments on Flyvbjerg's Rationality and Power." International Planning Studies, 6(3): 257-262.

31. Pheage, T. (2017). "Dying from Lack of Medicines." Africa Renewal, (December 2016March 2017), pp. 24-25. https://www.tralac.org/ images/docs/11064/un-africa-renewal-december2016.pdf (accessed 9 January 2021).

32. Qayad, M. G. (2007). "Health Care Service in Transitional Somalia: Challenges and Recommendations." Bildhaan, vol. 7, pp. 190-210.

33. Reinke E, Supriyatiningsih J. H. (2017). "Maternal Mortality as a Millennium Development Goal of the United Nations: A Systematic Assessment and Analysis of Available Data in Threshold Countries Using Indonesia as Example. Journal of Global Health. 7(1): 010406.

34. Say, L., Chou, D., Gemmill, A., Tunçalp, Ö., Moller, A., Daniels, J., Gülmezoglu, A. M., Temmerman, M., and Alkema, L. (2014). "Global Causes of Maternal Death: A WHO Systematic

Analysis." The Lancet. 2(6):e323-e333. https://www.thelancet.com/journals/langlo/article/ PIIS2214-109X(14)70227-X/fulltext

35. Sobrinho, N., and Thakoor, V.V. (2019). More Sand than Oil: Sub-Saharan Africa Stands to Gain More from Reducing Corruption than Any Other
Region. Finance \& Development, Vol. 56, No. 3.

36. Soy, S. K. (1997). "The Case Study as a Research Method," unpublished paper, University of Texas at Austin.

37. Sparkman, L. (2020). "Reducing Maternal Mortality: Steps to Improve Outcomes."

38. https://www.relias.com/blog/reducing-maternalmortality (accessed 20 December 2020)

39. Tikkanen, M. (2011). "Placenta Abruption: Epidemiology, Risk Factors and Consequences." Acta Obstetricia Et Gynecologica Scandinavica, 90(2):140-149.

40. Tikkanen, R., Gunje, M. Z, FitzGerald, M., and Zephyrin, L. (2020). "Maternal Mortality and Maternal Care in the United States Compared to 10 Other Developed Countries." At: https://www.commonwealthfund.org/publications/is sue-briefs/2020/nov/maternal-mortality-maternitycare-us-compared-10-countries (accessed 16 March 2021)

41. Varrella, S. (2020). "African Countries with the Highest Maternal Mortality Rate in 2017." At: https://www.statista.com/statistics/1122869/mater nal-mortality-rate-in-africa-by-country/ (accessed 18 November 2020).

42. World Health Organization (2011). "International Statistical Classification of Diseases and Related Health Problems," $10^{\text {th }}$ Revision. Available: http://www.who.int/classifications/icd/ICD10Vol me2_en_2010.pdf?ua $=1$.(accessedM10NJanuary 2021)

43. World Health Organization https://www.who.int/news-room/fact-

(2019). sheets/detail/maternal- mortality (accessed 13 October 2020)

44. World Health Organization: https://www.who.int/data/gho/indicator-metadataregistry/imr- details/26 (accessed 23 September 2020)

45. World Health Organization: https://www.who.int/health-topics/maternalhealth\#tab=tab_1 (accessed 6 October 2020)

46. World Population Review: https://worldpopulationreview.com/countries/som alia-population (accessed 20 April, 2021)

47. World Health Organization WHO, UNICEF, UNFPA, World Bank Group and the United Nations Population Division (2019). Trends in Maternal Mortality 2000 to 2017: Estimates by WHO, UNICEF, UNFPA, World Bank Group and 
the United Nations Population Division. Geneva: World Health Organization.

48. World Health Organization, WASH Cluster, Health Cluster \& UNICEF (nd.): available at: https://moh.gov.so/en/wpcontent/uploads/2020/12/ Cholera-Preparedness-and- Response- Planfor-Somalia1-Final.pdf (accessed 7 May 2021)
49. World Health Organization (n.d.), Report of the WHO Mission to Somalia 11-17 September 2015, "Strategic Review of the Somali Health Sector: Challenges and Prioritized Actions." Available at: http://somaliangoconsortium.org/download/57857 1d68d08f/ (accessed 7 March 2021) 